
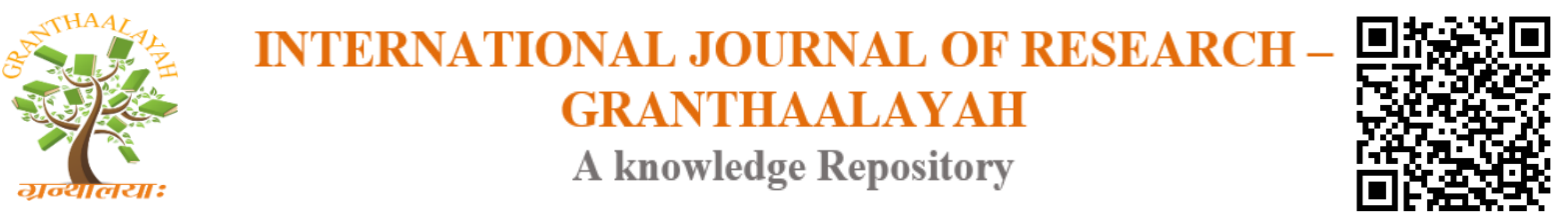

Science

\title{
AUTHORSHIP PATTERN \& COLLABORATION IN ETRI JOURNAL: A SCIENTROMETRIC STUDY
}

\author{
Richa Narzary $^{* 1}$, C. Murugan ${ }^{2}$ \\ ${ }^{* 1,2}$ Department of Library and Information Science, Periyar University, Tamilnadu, India
}

\begin{abstract}
This study aims to evaluate the publications in ETRI Journal during the year 2010-2016. The data were retrieved from the web of science database maintained by Thomson Reuters, analyzed using tools like HisCite and Microsoft Excel. The adopts various method like Relative growth rate, doubling time, Exponential Growth Rate, Average Authors per Paper, Degree of collaboration etc. focusing on various aspect of the journal such as document types, year wise distribution of publication, authorship pattern, authors productivity, institutions involved, relative growth rate, degree of collaboration, countries wise, most prolific authors of the journal and keyword wise distribution etc. The study reveals that ETRI journal has come out with 7volumes, 42 issues and total publications of 936 articles. The highest number of publications in terms of articles was in the year 2013 followed by 2012. The study shows that most of the papers $(98.46 \%)$ were contributed jointly whereas $(1.6 \%)$ papers were contributed by single authors. It reveals that Kim $\mathrm{J}$ is the most productive author contributing $58(6.2 \%)$ of articles in ETRI journals. The country wise distribution shows that highest number of contribution comes from the South Korea itself a total record showing 656, (70.1\%). ETRI itself is the top most contributors in ETRI Journal and the word "Based" is the most common key word used, with total of $228(24.4 \%)$ records.
\end{abstract}

Keywords: Scientometric; ETRI Journal; Web of Science; Authors Productivity; HisCite.

Cite This Article: Richa Narzary, and C. Murugan. (2017). "AUTHORSHIP PATTERN \& COLLABORATION IN ETRI JOURNAL: A SCIENTROMETRIC STUDY.” International Journal of Research - Granthaalayah, 5(7), 608-622. 10.29121/granthaalayah.v5.i7.2017.2170.

\section{Introduction}

In this competitive world of knowledge, information and education where there is a lot of thirst for gaining information through various ways and means, as lots of information and knowledge are available through various sources like through published journals, articles through internet by various authors, scholars etc. there lies an importance for both the authors and readers of those article to assess the performance and quality of those articles. 
Bibliometric is the type of research method which is a fast emerging area in the field of Library and Information Science. Bibliometric analysis is increasingly gaining its importance, to measure and assess research impact of individuals, groups of individuals or institutions. The word "Bibliometrics" refers to the application of mathematics to study bibliography. It has been derived from two Greek words "Biblio" meaning books and "metric" meaning measure. Pritchard, (1969), defined Bibliometrics as 'the application of mathematical and statistical methods in scientific literature'. Similarly, Roy, (1983) stated that Bibliometrics is 'the study of the process of information use by analyzing the characteristics of literatures and their distribution by mathematical method'; as it plays important role in terms of research evaluation, scientific research assessment and publication rankings (Mattson, 2008). Furthermore, bibliometric can be a standard for weeding and collection development in a library. Jacobs, (2001) opines that bibliometrics studies helps in indication of scientific productivity, trends in researcher performance for publication, and journal rankings etc. In the field of library and information science

Bibliometric analysis along with scientometrics is often used for conducting quantitative analysis of academic literature, exploring the impact in the field of particular research work or to know the impact of a group of researchers, or the impact of a particular articles, scrutinize the impact of journals and institutes, to understand the scientific citations, mapping of scientific fields and the construction of indicators for use for policy purpose and in the context of management etc. which is further illustrated by the work of Haitun, (1983) who treats 'Scientometrics', as scientific disciplines, which performs reproducible measurements of scientific activity. In the present day context scientometrics is regarded as one of interdisciplinary research fields which is extended to almost all scientific fields. As the Scientometric studies are mostly applied to measure scientific activities, mainly by producing statistics on scientific publications indexed in databases, which are extremely valuable methods for evaluating research output, to know about the author productivity, citation analysis in science and technology, to measure and describe countries, universities, research institutes, journals, specific research topics and specific disciplines.

Authors like Rajendran, P., Jeyshankar, R., \& Elango, B. (2011) conducted a scientometric analysis of 633 research articles published in Journal of Scientific and Industrial Research which has been carried out. Five Volumes of the journal containing 60 issues from 2005 to 2009. Their analysis coverered mainly the number of contributions, authorship pattern \& author productivity, average citations, average length of articles, average keywords and collaborative papers etc. Out of 633 contributions, 51 were found single authored and rest by multi authored with degree of collaboration 0.92 and week collaboration among the authors. Pattern of Co-Authorship revealed that the improving trend of co-authored papers. The study revealed that the author productivity is 0.34 and mostly dominated by the Indian authors.

Similarly, Murugan, C., \& Balasubramani, R., (2012) in their article titled Scientometric Mapping of Remote Sensing Research Output: A Global Perspective; used Scientometric in order to undertake quantitative analysis of remote sensing, in terms of research output throughout the world during 1975 - FEB 2010. In order to analyze various aspects like number of papers published and the cited references, country wise publications, productive authors, number of institutions involved in the research, most preferred journal, most preferred language by scientist 
etc. During their study period, 1,188 articles were published and cited references were 30,654. Their result indicated that average number of publications published per year was 38.07.

Khaparde, V., \& Pawar, S. (2013) examined the trends in authorship pattern and author's collaborative research in Information Technology with a total sample of 17917 articles collected from LISA during 2000-2009. Their result showed that average number of authors per article is 1.80. The degree of collaboration is 0.71 . The multi- authorship articles were found to be higher and predominant than single authorship.

Singh, H. (2013) analyzed various bibliometric components of the articles published in the Chinese Librarianship: An International Electronic Journal between 2009 and 2012. Various quality aspects of the 55 articles published in the period were studied. His result showed the quantitative growth of articles by number and year, distribution of citations by number and year, range of citations per article, authorship patterns, authorship productivity, most prolific authors, and authors by country.

Velmurugan, C. (2014) has analyzed with 546 contributions published in the Indian Journal of Pure and Applied Physics (IJPAP) during the period of 2009 to 2012 . He attempted to analyze and discuss each article, year wise and volume wise authorship, author's productivity and the single and multi-authored papers of the journal. The findings of the results revealed that the maximum number of contributions i.e., 149 (27.29 \%) were published in the year 2012 whereas the minimum number of $121(22.17 \%)$ was published in the year 2011 . The highest number of author productivity i.e., 420 (6.56) were found to be published in the year 2010.

Mani, K. T. (2014) conducted a bibliometric study of Malaysian Journal of Library and Information Science. The result of the study revealed that total number of 279 articles and 575 authors were published. The analysis indicated the growth of contributions by year and volume, authorship patterns by year and volume, authorship patterns, author productivity, single and multi-authored papers by year, authorship patterns by global, most prolific contributors and degree of collaboration. Maximum number of contributions i.e., 28 (10.036\%) were published in the year 2011. Average number of authors per paper is 2.06. The highest number of author productivity i.e., $72(12.522 \%)$. Majority $180(64.516 \%)$ of the total contributions represent collaborative research. The average degree of collaboration has come out with 0.64 during the study period.

Rubinandhini, A., \& Gomathi, P. (2015) studied the authorship Pattern in journal from Webology. This study covered the total number of 57 articles considered one journal with five years (2010 to 2014). This paper discusses on various aspect such as authorship pattern, citation analysis, Publication Efficiency Index, length of articles, relative growth rate, Distribution of year wise citation analysis, degree of collaboration, country wise distribution of publications, and time series analysis of total authored papers.

Oh, D. G., Yeo, J. S., \& Park, S. H. (2015) analyzed various aspects of success factors in the development of the ETRI Journal which has been published by the Electronic and Telecommunications Research Institute, Korea. The results showed that it is enlisted in SCI within 3 years after preparing for enlisting in it based on the support from ETRI as well as the 
cooperation from the members of the institution. From the first year (1996) when preparing the enlisting in SCI, the numbers of the articles published in each issue have been increased, and the members in ETRI have cooperated to publish their articles in the journal and cite the articles from the journal in their own articles and proceedings. The case of ETRI Journal shows that the journal published by institution can, be the first stage of its publication, take full advantage of its characteristics as an institution.

Taking into consideration the previous study and the importance of scientometric in the field of library science; this paper tries to focus and understand the scientific activities of "ETRI JOURNAL" by applying scientometric techniques. ETRI Journal is the official bimonthly journal of Electronics and Telecommunications Research Institute (ETRI), Daejeon, Rep. of Korea. Electronic and Telecommunication Research Institute ETRI was established in the year 1976. Which is a nonprofit Korean government funded research institution. The purpose of ETRI Journal is to circulate information regarding innovative technological ideas in the fields of information, telecommunications, and electronics within the R\&D scope of ETRI. The ETRI Journal publishes research papers in English in the fields of information, telecommunications, and electronics; particularly in areas like Telecommunications Basic Technology, Microelectronics Technology, Network and Internet Technology, Radio \& Broadcasting Technology, Mobile Telecommunications Technology, Computer \& Software Technology, Big Data Information Technology, Information Security, IT Convergence Technology and Information Technology Strategy etc.

As we can see from the review that previous study only considered the Success Factors of International Journal by Institution in ETRI Journal failing to explore and answer the other important factors like articles published, present authorship pattern, relative growth rate and doubling time, author's productivity, exponential growth rate, document wise distribution of publication, institutions wise distribution of publication, keyword used, country wise distribution of the publications etc. The present study tries to explore and put forward the result for further development of ETRI Journal

\section{Methodology}

This study is based on explorative and descriptive research approach as bibliometric analysis, is an exploratory in nature that describes the quantity, characteristics, and productivity of global publication in field of Library and Information Science (LIS).

The sample selected for the study is Electronic and Telecommunication Research Institute (ETRI) Journal. The period of the study is 2010-2016 (seven years). All the data necessary for the present study has been retrieved from Web of Science database, which is published by Thomson Reuters; using the key word "ETRI Journal" as publication name. A total of 936 articles published in ETRI Journal consisting of seven volumes and forty-two issues have been collected and used for the present study. The data collected were recorded and analyzed with the help of MS - Excel and HistCite software. The study also tries to adopt various method like Relative growth rate and doubling time, Exponential Growth Rate, Average Authors per Paper (AAPP), Degree of collaboration etc. 


\section{Analysis and Interpretation}

Table No.1 depicts the total number of publications in ETRI Journal from 2010 to 2016; it also presents the information of number of issues, volume No. and percentage of publications yearly during the selected period of study (2010-2016). The results presented in Table No.1 below reveals that from 2010 to 2016, ETRI journal has come out with seven volumes, 42 issues and total publications of 936 articles.

Table 1: Year wise distribution of articles

\begin{tabular}{|l|l|l|l|l|}
\hline Year & Volume No. & Issues & Total Publications & Percentage \\
\hline 2010 & 32 & 6 & 137 & 14.6 \\
\hline 2011 & 33 & 6 & 134 & 14.3 \\
\hline 2012 & 34 & 6 & 141 & 15.1 \\
\hline 2013 & 35 & 6 & 155 & 16.6 \\
\hline 2014 & 36 & 6 & 133 & 14.2 \\
\hline 2015 & 37 & 6 & 129 & 13.8 \\
\hline 2016 & 38 & 6 & 107 & 11.4 \\
\hline 7 Years & 7 Volumes & $\mathbf{4 2}$ Issues & $\mathbf{9 3 6}$ Articles & $\mathbf{1 0 0}$ \\
\hline
\end{tabular}

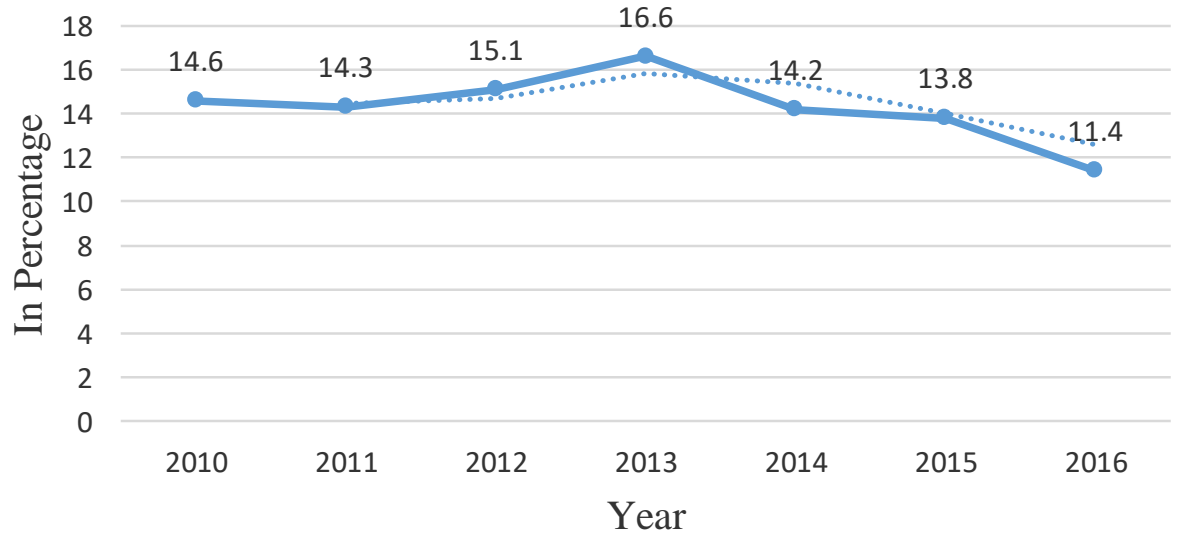

Figure 1: Year wise percentage of total articles published during (2010-16)

Figure No.1 shows the year wise percentage of Articles published in ETRI Journal from the year 2010 to 2016. It also shows the trend in articles published. The results as depicted in the figure reveals that the highest number of Articles publications was in the year 2013, 16.6\% of the total articles published in seven years i.e. 155 out of total 936 articles as shown in Table No.1. The second highest publications were in the year 2012 i.e. $15.1 \%$ of the total articles published. During this seven years' period the lowest number of publications is observed during the year 2016, (11.4\% of the total articles published). The trend line in figure No.1. indicates that there is an increasing trend in number of articles published, from the year 2010 to 2013 . But after 2013 a continuous decreasing trend in articles published could be seen as shown in Figure No. 1. 
Table 2: Year wise Authorship Pattern of Publications

\begin{tabular}{lllllllllllll}
\hline Year/Author & $\mathbf{1}$ & $\mathbf{2}$ & $\mathbf{3}$ & $\mathbf{4}$ & $\mathbf{5}$ & $\mathbf{6}$ & $\mathbf{7}$ & $\mathbf{8}$ & $\mathbf{9}$ & $\mathbf{1 0}$ & $\mathbf{1 0 +}$ & Total \\
\hline $\mathbf{2 0 1 0}$ & 14 & 66 & 108 & 116 & 65 & 42 & 28 & - & 9 & - & - & 448 \\
\hline $\mathbf{2 0 1 1}$ & 8 & 70 & 78 & 128 & 90 & 60 & - & 40 & - & - & - & 474 \\
\hline $\mathbf{2 0 1 2}$ & 7 & 54 & 120 & 104 & 95 & 84 & 42 & 8 & 9 & - & - & 523 \\
\hline $\mathbf{2 0 1 3}$ & 9 & 52 & 123 & 140 & 100 & 78 & 49 & 8 & 9 & 20 & - & 588 \\
\hline $\mathbf{2 0 1 4}$ & 8 & 64 & 87 & 108 & 90 & 54 & 35 & 8 & 18 & - & 22 & 494 \\
\hline $\mathbf{2 0 1 5}$ & 5 & 52 & 114 & 120 & 65 & 30 & 63 & 8 & - & - & 23 & 480 \\
\hline $\mathbf{2 0 1 6}$ & 3 & 40 & 90 & 84 & 80 & 36 & 28 & 24 & 18 & - & 27 & 430 \\
\hline Total & $\mathbf{5 4}$ & $\mathbf{3 9 8}$ & $\mathbf{7 2 0}$ & $\mathbf{8 0 0}$ & $\mathbf{5 8 5}$ & $\mathbf{3 8 4}$ & $\mathbf{2 4 5}$ & $\mathbf{9 6}$ & $\mathbf{6 3}$ & $\mathbf{2 0}$ & $\mathbf{7 2}$ & $\mathbf{3 4 3 7}$ \\
\hline Percentage (\%) & 1.6 & 11.6 & 21.0 & 23.3 & 17.0 & 11.2 & 7.1 & 2.8 & 1.8 & 0.6 & 2.1 & $\mathbf{1 0 0}$ \\
\hline
\end{tabular}

Table No.2 shows the year wise authorship pattern of publications in ETRI journal. It shows year wise and number of Authors whether single author, joint authorship, consisting of two authors, three authors, four authors, up to ten plus authorship pattern. As per the result depicted in Table No.2., highest number of paper published in seven years' period from 2010 to 2016 is by group consisting of four authors; total of 800, (23.3\%) of total publications, followed by group of three authors, total of $720,(21 \%)$ of total publications and third highest contribution comes from group of five authors a total of $585,(17 \%)$ of total publications. $0.6 \%$ of total publications come from group of ten authors and single author contributes $1.6 \%$ of total publications. From Table No. 2 above we can sort the authorship pattern based on their percentage of total contribution from highest to lowest in following way, $\left(4,3,5,2,6,7,8,10+, 9,1\right.$, and 10) ${ }^{1}$ respectively.

Table 3: Single vs. Multi Authors

\begin{tabular}{|l|l|l|l|}
\hline Sl.No & Authorship pattern & Publication & Percent \\
\hline 1 & Single Author & 54 & 1.6 \\
\hline 2 & Multi-Authors & 3383 & 98.38 \\
\hline & Total & $\mathbf{3 4 3 7}$ & $\mathbf{1 0 0}$ \\
\hline
\end{tabular}

Table No. 3 shows the segregation of authorship pattern, between single author and multiple authors based on their publications. It shows that in ETRI Journal the contribution of single author in terms of publication is only 54 out of 3437 total publications and constitute $1.6 \%$ of total publications. Whereas that of multiple author is 3383 out of 3437 total publications and constitute $98.38 \%$ of total publications. Thus giving an indication that most of the publications are in the form of multiple authors during the selected period of this study when compared to single author.

Table 4: Prolific Author's wise distribution of articles (Top Twenty)

\begin{tabular}{|l|l|l|l|l|l|}
\hline Sl.No & Author & Records & Percent & TLCS & TGCS \\
\hline 1 & Kim J & 58 & 6.2 & 50 & 236 \\
\hline 2 & Lee J & 49 & 5.2 & 42 & 209 \\
\hline
\end{tabular}

\footnotetext{
${ }^{1}$ Numbers in the bracket indicates group of authors, for example: 4 means, publications by group of four authors, 1 means, single author and $10+$ means, publications by group of more than 10 authors.
} 


\begin{tabular}{|l|l|l|l|l|l|}
\hline 3 & Lee S & 30 & 3.2 & 15 & 119 \\
\hline 4 & Lee JH & 28 & 3.0 & 17 & 71 \\
\hline 5 & Kim H & 27 & 2.9 & 21 & 87 \\
\hline 6 & Lee H & 24 & 2.6 & 13 & 92 \\
\hline 7 & Kim S & 23 & 2.5 & 18 & 98 \\
\hline 8 & Kim K & 18 & 1.9 & 11 & 51 \\
\hline 9 & Kim M & 18 & 1.9 & 11 & 56 \\
\hline 10 & Park J & 16 & 1.7 & 5 & 28 \\
\hline 11 & Kim KH & 15 & 1.6 & 24 & 67 \\
\hline 12 & Kim Y & 15 & 1.6 & 13 & 68 \\
\hline 13 & Lee Y & 15 & 1.6 & 8 & 25 \\
\hline 14 & Kang S & 14 & 1.5 & 12 & 27 \\
\hline 15 & Lee D & 13 & 1.4 & 6 & 52 \\
\hline 16 & Choi JS & 12 & 1.3 & 18 & 76 \\
\hline 17 & Choi KS & 12 & 1.3 & 43 & 148 \\
\hline 18 & Kim JH & 12 & 1.3 & 2 & 38 \\
\hline 19 & Lee HS & 12 & 1.3 & 7 & 43 \\
\hline 20 & Lim S & 12 & 1.3 & 6 & 35 \\
\hline
\end{tabular}

Table No. 4 shows the top twenty Prolific Author's wise distribution of articles Publications records, percentage share of authors out of total publications, total local citation counts and total global citation counts. The top twenty authors in ETRI journal are viz. Kim J, Lee J, Lee S, Lee JH, Kim H, Lee H, Kim S, Kim K, Kim M, Park J, Kim KH, Kim Y, Lee Y, Kang S, Lee D, Choi $J S$, Choi KS, Kim JH, Lee HS, Lim $S$ respectively. It reveals that Kim J is the most productive author contributing $58(6.2 \%)$ of articles in ETRI journals, followed by Lee J with 49 (5.2\%) of articles and Lee $\mathrm{S}$ with 30 (3.2\%) articles respectively. From the table given above we can see that $\operatorname{Kim} K$, Kim $M$ has same number of publication records that is 18 , same percentage of contribution (1.96\%) and same number of total local citation counts only difference could be seen in total global citation counts where $\operatorname{Kim} M$ has 56 and $\operatorname{Kim} K$ as 51. Further same pattern could be seen for authors like $\operatorname{Kim} K H$, $\operatorname{Kim} Y$, and Lee $Y$, where number of publications records and their percentage of contribution are same that is $15(1.6 \%)$, but difference could be seen among the three separate authors in terms of their TLCS $(24,13,8)$ and TGCS $(67,68,25)$. Again likewise five different authors; Choi JS, Choi KS, Kim JH, Lee HS, Lim S, has same percentage of contribution and publications records of 12 (1.3\%). Though percentage of contribution and records are same among this five different authors, there is a difference in TLCS $(18,43,2,7,6)$ and TGCS $(76,148,38,43,35)$.

Table 5: Relative growth rate and doubling time

\begin{tabular}{|c|c|c|c|c|c|c|c|c|}
\hline Year & Total articles & $\begin{array}{l}\text { Cumulative } \\
\text { total }\end{array}$ & W1 & W2 & $\begin{array}{l}\text { (W2- } \\
\text { W1) }\end{array}$ & $\begin{array}{l}\text { Mean } \\
\text { R (a) } \\
(\mathbf{1 - 2})\end{array}$ & $\begin{array}{l}\text { Doubling } \\
\text { Time Dt(a) }\end{array}$ & $\begin{array}{l}\text { Mean } \\
\text { Dt(a) } \\
(1-2)\end{array}$ \\
\hline 2010 & 137 & - & 4.91 & - & 0.69 & \multirow{3}{*}{1.07} & 1.00 & \multirow{3}{*}{0.7} \\
\hline 2011 & 134 & 271 & 4.89 & 5.60 & 1.13 & & 0.61 & \\
\hline 2012 & 141 & 412 & 4.94 & 6.02 & 1.4 & & 0.49 & \\
\hline
\end{tabular}




\begin{tabular}{|c|c|c|c|c|c|c|c|c|}
\hline 2013 & 155 & 567 & 5.04 & 6.34 & 1.51 & \multirow{3}{*}{1.78} & 0.45 & \multirow[b]{2}{*}{0.39} \\
\hline 2014 & 133 & 700 & 4.89 & 6.55 & 1.83 & & 0.37 & \\
\hline 2015 & 129 & 829 & 4.85 & 6.72 & 1.99 & & 0.34 & \\
\hline 2016 & 107 & 936 & 4.67 & 6.84 & & 1.43 & & 0.55 \\
\hline
\end{tabular}

FORMULA

$D t(a)=\frac{0.693}{R(a)}$

$$
R(1-2)=\frac{W 2-W 1}{T 2-T 1}
$$

Table No.5 indicates that the Relative Growth Rate of total contributions which has gradually increased. The growth rate in 2010 is 0.69 , which was increased up to 1.99 in 2016 . The mean relative growth rate during the period of 2010-2012 was 1.07 and it was increased in the year 2013- 2016 which was 1.78. It shows that Relative Growth Rate of publication of ETRI Journal which has attained increasing trend. And at the same time doubling time got decreased from 1.00 to 0.34 (2010 to 2016). The mean doubling time during the period 2010- 2012 was 0.7 and it was increased during 2013- 2016 (0.39). Doubling Time ETRI Journal has got decreasing trend.

Table 6: Exponential Growth Rate

\begin{tabular}{|l|l|l|l|}
\hline Sl.No. & Year & Publication & Exponential Growth rate \\
\hline 1 & 2010 & 137 & - \\
\hline 2 & 2011 & 134 & 0.98 \\
\hline 3 & 2012 & 141 & 1.05 \\
\hline 4 & 2013 & 155 & 1.1 \\
\hline 5 & 2014 & 133 & 0.86 \\
\hline 6 & 2015 & 129 & 0.97 \\
\hline 7 & 2016 & 107 & 0.83 \\
\hline Total & & $\mathbf{9 3 6}$ & $\mathbf{5 . 7 9}$ \\
\hline
\end{tabular}

Table No.6 reveals the Exponential Growth Rate of publications in ETRI Journal during period 2010- 2016 (7 years). The highest growth rate (1.1) was found in 2013 with 155 Publications, followed by the year 2012 with the highest growth rate of 1.05 (141 publications). The lowest growth rate (0.83) was found in 2016 with 107 publications, followed by the year 2014 with the lowest growth rate of 0.86 (133 publications). It is also found that the Exponential Growth Rate was found to be 5.79 .

Table 7: Author Productivity (Productivity Per Authors)

\begin{tabular}{|l|l|l|l|l|l|}
\hline Sl. No & Year & Total No. of Papers & Total No. of Authors & AAPP & $\begin{array}{l}\text { Productivity } \\
\text { Per Authors }\end{array}$ \\
\hline 1 & 2010 & 137 & 448 & 3.270 & 0.305 \\
\hline 2 & 2011 & 134 & 474 & 3.537 & 0.282 \\
\hline 3 & 2012 & 141 & 523 & 3.709 & 0.269 \\
\hline 4 & 2013 & 155 & 588 & 3.793 & 0.263 \\
\hline
\end{tabular}




\begin{tabular}{|l|l|l|l|l|l|}
\hline 5 & 2014 & 133 & 494 & 3.714 & 0.269 \\
\hline 6 & 2015 & 129 & 480 & 3.720 & 0.268 \\
\hline 7 & 2016 & 107 & 430 & 4.018 & 0.248 \\
\hline Total & $\mathbf{9 3 6}$ & $\mathbf{3 4 3 7}$ & $\mathbf{3 . 6 7 2}$ & $\mathbf{0 . 2 7 2}$ \\
\hline
\end{tabular}

*Average Authors per Paper (AAPP) $=$ Number of authors/ Number of papers. Productivity per author $=$ Number of papers/ Number of authors.

Table No.7 shows the data related to author productivity, which shows that the total average number of authors per paper is 3.672 and the average productivity per author is 0.272 . The highest number of author productivity i.e., 588 (3.793) were published in the year 2013.

Table 8: Degree of Collaboration

\begin{tabular}{|l|l|l|l|}
\hline Year & Single Author & Multiple Author & Degree of collaboration \\
\hline 2010 & 14 & 434 & 0.96 \\
\hline 2011 & 8 & 466 & 0.98 \\
\hline 2012 & 7 & 516 & 0.98 \\
\hline 2013 & 9 & 579 & 0.98 \\
\hline 2014 & 8 & 486 & 0.98 \\
\hline 2015 & 5 & 475 & 0.98 \\
\hline 2016 & 3 & 427 & 0.99 \\
\hline Total & $\mathbf{5 4}$ & $\mathbf{3 3 8 3}$ & $\mathbf{0 . 9 8}$ \\
\hline
\end{tabular}

Table No.8 shows the degree of author collaboration. The formula given by K. Subramaniyam was used. The Formula is:

$C=\frac{N M}{N M+N S}$

Where,

$\mathrm{C}=$ degree of collaboration,

$\mathrm{Nm}=$ Number of multi-authored works,

Ns= Number of single-authored works.

The degree of author collaboration which has shown an increasing trend during the study period. This brings out the high level of prevalence of collaborative research in the field of ETRI JOURNAL. The analysis on the extent of collaboration of ETRI JOURNAL research reveals fact that Degree of collaboration had an initial value of 0.96 per cent in the year 2010 and this trend was increased to 0.99 per cent in the year 2016. There was a decreasing trend on single authored papers and an increasing trend on multi authored papers. It is evident that Subramanian's formula led collaboration in this investigation through regression analysis.

Table 9: Document wise distribution of Publications

\begin{tabular}{|l|l|l|l|l|l|}
\hline Sl.No & Document Type & Records & Percent & TLCS & TGCS \\
\hline 1 & Articles & 921 & 98.4 & 460 & 3036 \\
\hline 2 & Editorial Material & 9 & 1.0 & 1 & 2 \\
\hline 3 & Letter & 4 & 0.4 & 2 & 15 \\
\hline 4 & Correction & 1 & 0.1 & 0 & 0 \\
\hline 5 & Review & 1 & 0.1 & 1 & 1 \\
\hline
\end{tabular}


Table No. 9 shows the document wise distribution of publications, like document type, percentage, TLCS and TGCS. It shows that most of the scholarly communications of scientific research are published in ETRI journal are in the form of articles a total of 921 (98.4\%), followed by Editorial Material 9 (1.0\%), Letters 4 (0.4\%), Correction $1(0.1 \%)$, and Review 1 $(0.1 \%)$ out of total Publications in seven years' period of this study. The minimum of publications is in the form of Correction and Review.

Table 10: Institutions wise distribution of publications (Top Twenty)

\begin{tabular}{|l|l|l|l|l|l|}
\hline Sl.No & Institution & Records & Percent & TLCS & TGCS \\
\hline 1 & ETRI & 403 & 43.1 & 309 & 1614 \\
\hline 2 & Korea University & 45 & 4.8 & 13 & 99 \\
\hline 3 & Korea Adv Inst Sci \& Technology & 42 & 4.5 & 26 & 116 \\
\hline 4 & Hanyang University & 40 & 4.3 & 16 & 109 \\
\hline 5 & Yonsei University & 34 & 3.6 & 22 & 98 \\
\hline 6 & Chungnam Natl University & 29 & 3.1 & 18 & 157 \\
\hline 7 & Inha University & 23 & 2.5 & 6 & 55 \\
\hline 8 & Kyung Hee University & 21 & 2.2 & 12 & 187 \\
\hline 9 & University Sci \& Technology & 21 & 2.2 & 20 & 96 \\
\hline 10 & Xidian University & 19 & 2.0 & 4 & 24 \\
\hline 11 & Chungbuk Natl University & 18 & 1.9 & 3 & 39 \\
\hline 12 & Seoul Natl University & 17 & 1.8 & 5 & 60 \\
\hline 13 & Sungkyunkwan University & 16 & 1.7 & 11 & 43 \\
\hline 14 & Kyungpook Natl University & 15 & 1.6 & 10 & 71 \\
\hline 15 & Chung Ang University & 13 & 1.4 & 4 & 43 \\
\hline 16 & Pusan Natl University & 12 & 1.3 & 6 & 27 \\
\hline 17 & Yeungnam University & 11 & 1.2 & 5 & 19 \\
\hline 18 & Beijing Univ Posts \& Telecommunication & 10 & 1.1 & 3 & 20 \\
\hline 19 & Ajou University & 9 & 1.0 & 4 & 35 \\
\hline 20 & Hanbat Natl University & 9 & 1.0 & 10 & 44 \\
\hline
\end{tabular}

Table No.10 shows the Institutions wise distribution of publications; for which only top twenty institutions that contributes in ETRI journal have been shown. Countries like; ETRI, Korea University, Korea Adv Inst Sci \& Technology, Hanyang University, Yonsei University, Chungnam Natl University, Inha University, Kyung Hee University, University Sci \& Technology, Xidian University, Chungbuk Natl University, Seoul Natl University, Sungkyunkwan University, Kyungpook Natl University, Chung Ang University, Pusan Natl University, Yeungnam University, Beijing Univ Posts \&Telecommunication, Ajou University, Hanbat Natl University; are the top twenty institutions. Table No. 10 shows that ETRI itself is the top most contributor in ETRI Journals with 403 records, (43.1\%), 309 TLCS and TGCS of 1614, then followed by the Korea University with 45 records, (4.8\%), 13 TLCS and TGCS 99, then next comes the Korea advanced institute of science and technology with 42 records, (4.5\%), TLCS 26 and TGCS 116. Top three positions as per the records are held by the Korean academic institutions. 
Table 11: Keyword wise distributions of publications (Top Twenty)

\begin{tabular}{|l|l|l|l|l|l|}
\hline SI.No & Word & Records & Percent & TLCS & TGCS \\
\hline 1 & BASED & 228 & 24.4 & 106 & 791 \\
\hline 2 & USING & 165 & 17.6 & 52 & 468 \\
\hline 3 & SYSTEM & 72 & 7.7 & 36 & 266 \\
\hline 4 & NETWORKS & 68 & 7.3 & 18 & 250 \\
\hline 5 & POWER & 67 & 7.2 & 39 & 213 \\
\hline 6 & HIGH & 61 & 6.5 & 37 & 240 \\
\hline 7 & ANALYSIS & 60 & 6.4 & 27 & 214 \\
\hline 8 & SYSTEMS & 60 & 6.4 & 24 & 164 \\
\hline 9 & METHOD & 58 & 6.2 & 24 & 188 \\
\hline 10 & SCHEME & 55 & 5.9 & 17 & 165 \\
\hline 11 & EFFICIENT & 50 & 5.3 & 25 & 187 \\
\hline 12 & ALGORITHM & 46 & 4.9 & 15 & 137 \\
\hline 13 & LOW & 46 & 4.9 & 22 & 135 \\
\hline 14 & DESIGN & 45 & 4.8 & 21 & 127 \\
\hline 15 & ANTENNA & 44 & 4.7 & 12 & 106 \\
\hline 16 & VIDEO & 41 & 4.4 & 26 & 122 \\
\hline 17 & WIRELESS & 41 & 4.4 & 14 & 204 \\
\hline 18 & DETECTION & 37 & 4.0 & 16 & 155 \\
\hline 19 & ADAPTIVE & 36 & 3.8 & 14 & 80 \\
\hline 20 & PERFORMANCE & 35 & 3.7 & 16 & 87 \\
\hline
\end{tabular}

Table No.11 Shows the top twenty Keyword wise distributions of publications in ETRI journals during the period of study i.e. from 2010 to 2016. The top twenty key word used are BASED, USING, SYSTEM, NETWORKS, POWER, HIGH, ANALYSIS, SYSTEMS, METHOD, SCHEME, EFFICIENT, ALGORITHM, LOW, DESIGN, ANTENNA, VIDEO, WIRELESS, DETECTION, ADAPTIVE, PERFORMANCE Based on records, percentage is calculated and depicted below separately in Figure No.3 below. From both, Table No. 11 and Figure No. 3 it can be shown that the word "Based" is the most common key word used during publications, with total of 228 (24.4\%) records, 106 TLCS and 791 TGCS. Next $2^{\text {nd }}$ most common key word used is 'Using' with records of 165 (17.6\%), TLCS 52 and TGCS 468. Third highest number of key word used while publications in ETRI journal is 'SYSTEM' with total record of 72, (7.7\%), 36 TLCS and 266 TGCS. 


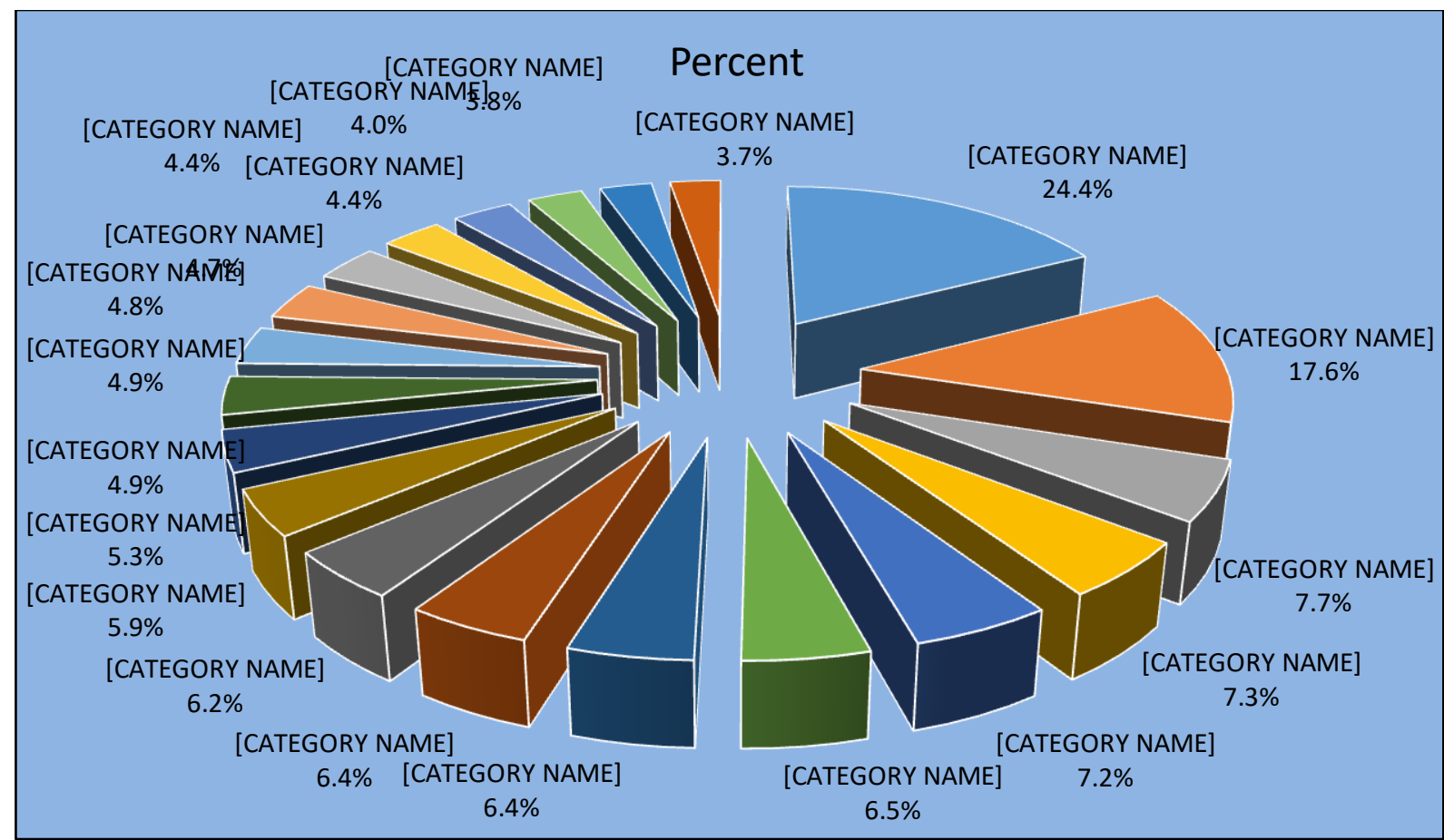

Figure 3: Percentage of Keyword wise distribution of publications (Top Twenty)

Table 12: Country wise distributions of publications (Top Twenty)

\begin{tabular}{|l|l|l|l|l|l|}
\hline Sl. No. & Country & Records & Percent & TLCS & TGCS \\
\hline 1 & South Korea & 656 & 70.1 & 395 & 2335 \\
\hline 2 & Peoples R China & 123 & 13.1 & 33 & 262 \\
\hline 3 & USA & 45 & 4.8 & 8 & 70 \\
\hline 4 & Iran & 35 & 3.7 & 11 & 74 \\
\hline 5 & India & 21 & 2.2 & 2 & 31 \\
\hline 6 & Taiwan & 15 & 1.6 & 7 & 113 \\
\hline 7 & Malaysia & 14 & 1.5 & 3 & 33 \\
\hline 8 & Spain & 12 & 1.3 & 5 & 39 \\
\hline 9 & UK & 10 & 1.1 & 3 & 61 \\
\hline 10 & Serbia & 8 & 0.9 & 1 & 20 \\
\hline 11 & Turkey & 7 & 0.7 & 2 & 49 \\
\hline 12 & Canada & 6 & 0.6 & 0 & 13 \\
\hline 13 & Unknown & 6 & 0.6 & 1 & 5 \\
\hline 14 & Japan & 5 & 0.5 & 2 & 21 \\
\hline 15 & Pakistan & 5 & 0.5 & 3 & 10 \\
\hline 16 & Thailand & 5 & 0.5 & 3 & 7 \\
\hline 17 & Egypt & 4 & 0.4 & 0 & 20 \\
\hline 18 & Germany & 4 & 0.4 & 4 & 20 \\
\hline 19 & Singapore & 4 & 0.4 & 2 & 30 \\
\hline 20 & Vietnam & 4 & 0.4 & 1 & 8 \\
\hline
\end{tabular}


Table No.12 shows the contribution of top 20 countries viz. South Korea, Peoples Republic of China, USA, Iran, India, Taiwan, Malaysia, Spain, UK, Serbia, Turkey, Canada, Unknown, Japan, Pakistan, Thailand, Egypt, Germany, Singapore, Vietnam in ETRI journal; in terms of records, percentage of contribution, total local citation counts and total global citation counts. The highest number of contribution comes from the South Korea itself a total record showing 656, (70.1\%), 395 total local citation counts and 2335 total global citation counts. Second highest contributions come from Peoples Republic of China a total of 123 records, (13.1\%), 33 total local citation counts, 262 total global citation counts and third highest contributor is USA a total of 45 records, $(4.8 \%), 8$ total local citation counts, 70 total global citation counts. India is on fifth position next to Iran with a total of 21 records, $(2.1 \%), 2$ total local citation counts, and 31 total global citation counts respectively.

\section{Findings and Conclusion}

In today's competitive world of knowledge, information and communication technology where there is a lot of thirst for gaining information through various sources, as lots of information and knowledge are available through various means like through published journals, articles through internet by various authors, scholars etc. there lies an importance for both the authors and readers of those article to know the performance and quality of those articles, so in such situation we have taken the case of ETRI Journals in order to have the complete overview of the performance of ETRI journals from 2010-2016 by taking into considerations various factors like document types, year wise distribution of publication, authorship pattern, institutions involved, countries wise contribution, most prolific authors of the journal and keyword wise distribution etc.

The study reveals that from 2010 to 2016, ETRI journal has come out with seven volumes, 42 issues and total publications of 936 articles. It also reveals that the highest number of Articles published was in the year 2013, (16.6\%) of the total articles published in seven years' period of study i.e. 155 out of total 936 articles.

The segregation of authorship pattern, between single author and multiple authors based on their publications also shows that the contribution by single author in terms of publication is only 54 out of 3437 total publications and constitute $1.6 \%$ of total publications. Whereas that of multiple author is 3383 out of 3437 total publications and constitute $98.4 \%$ of total publications. Thus giving an indication that most of the publications are in the form of multiple authors during the selected period of this study when compared to single author. It is clear from the Authorship pattern, highest number of publications are from four authors $800,(23.3 \%)$.

Apart from the authorship pattern the authors also tries to report the top twenty Prolific Author's based on Publications records, percentage share of authors out of total publications, total local citation counts and total global citation counts. The top twenty authors in ETRI journal are viz. Kim J, Lee J, Lee S, Lee JH, Kim H, Lee H, Kim S, Kim K, Kim M, Park J, Kim KH, Kim Y, Lee Y, Kang S, Lee D, Choi JS, Choi KS, Kim JH, Lee HS, Lim S respectively. It reveals that $\mathrm{Kim} \mathrm{J}$ is the most productive author contributing $58(6.2 \%)$ of articles in ETRI journals.

The study period has witnessed an overall mean relative growth rate in 1.43 . The mean doubling time of publication for the periods of 2010- 2016 was 0.55 . It is also found that the Exponential 
Growth Rate was found to be 5.79. The highest number of author productivity i.e., 588 (3.793) were published in the year 2013. The degree of collaboration range started from $0.96-0.99$ during 2010 to 2016 . The overall study period degree of collaboration range is 0.98 .

It reveals that most of the scholarly communications of scientific research published in ETRI journal are in the form of articles with a total of 921 (98.4\%). The minimum numbers of publications are in the form of Correction and Review.

The study reveals that ETRI itself is the top most contributors in ETRI Journals with 403 records, (43.1\%), 309 TLCS and TGCS of 1614

Keyword wise distribution of publications in ETRI journals during the period from 2010 to 2016; shows top twenty key word used by the researcher in their scholarly communications. Based on records, percentage calculated and it is found that the word "Based" is the most common key word used during publications, with total of 228 (24.4\%) records, 106 TLCS and 791 TGCS.

The country wise distribution of publications, shows contribution of top 20 countries which are viz. South Korea, Peoples Republic of China, USA, Iran, India, Taiwan, Malaysia, Spain, UK, Serbia, Turkey, Canada, Unknown, Japan, Pakistan, Thailand, Egypt, Germany, Singapore, Vietnam in ETRI journal; The highest number of contribution comes from the South Korea itself a total record showing 656, (70.1\%), 395 total local citation counts and 2335 total global citation counts.

The findings of the Scientometric study on ETRI journal presented above provide a gist about the overall scenario of ETRI journal from the year 2010-2016. Thus acting as guide for the researcher in the fields of information, telecommunications, electronics and subscriber of ETRI journal by providing ample information on various aspects like number of publication, between the time period, types of document published, authorship pattern, country wise contribution, top institution contribution, list of prolific authors, most common key word used etc. The overall findings of this study are important for the researcher/ institutions/ contributors because it will help in better and further performance of ETRI journal.

\section{References}

[1] Haitun, S. D. (1983). Scientometrics: State and Perspectives. Science, 8, 48-54.

[2] Jacobs, D. (2001). A bibliometric study of the publication patterns of scientists in South Africa 1992-96, with special reference to gender difference. In ISSI-2001: International Society for Scientometrics and Informetrics. International conference (pp. 275-285).

[3] Mani, K. T. (2014). Authorship Patterns and Collaborative Research in Malaysian Journal of Library and Information Science, 1996-2012.

[4] Mattson, P. (2008). Bibliometrics: an important tool in research evaluation. The Euroscientist, 5.

[5] Murugan, C., \& Balasubramani, R. (2012). Scientometric Mapping of Remote Sensing Research Output: A Global Perspective. Library Philosophy \& Practice.

[6] Oh, D. G., Yeo, J. S., \& Park, S. H. (2015). An Analysis on the Success Factors of International Journal by Institution: With a Special Regard to the Case of the ETRI Journal. Journal of the Korean Society for information Management, 32(3), 361-375.

[7] Pritchard, A. (1969). Statistical bibliography or bibliometrics. Journal of Documentation, 25, 348. 
[8] Khaparde, V., \& Pawar, S. (2013). Authorship pattern and degree of collaboration in Information Technology. Journal of Computer Science \& Information Technology, 1(1), 46-54.

[9] Rajendran, P., Jeyshankar, R., \& Elango, B. (2011). Scientometric analysis of contributions to Journal of Scientific and Industrial Research. International Journal of Digital Library Services, 1(2), 79-89.

[10] Rubinandhini, A., \& Gomathi, P. (2015). Authorship Pattern on Annals of Library and Information Studies Output During 2005-2014: A Bibliometric Study. International Journal of Engineering Sciences and Management Research, 2(9), 141-151.

[11] Roy, P. M. (1983). Towards a theory of citing in citation analysis studies. Developing Horizons in Library and Information Science, 1, 223-35.

[12] Singh, H. (2013). A bibliometric analysis of the Chinese Librarianship: An International Electronic Journal, 2009-2012. Chinese Librarianship: An International Electronic Journal, 35, $16-27$.

[13] Velmurugan, C. (2014). Authorship pattern and collaborative research output of Indian Journal of Pure and Applied Physics (IJPAP). International Journal of Art \& Humanity Science (IJAHS), 1(2), 37-41.

*Corresponding author.

E-mail address: ranteng01@ gmail.com 